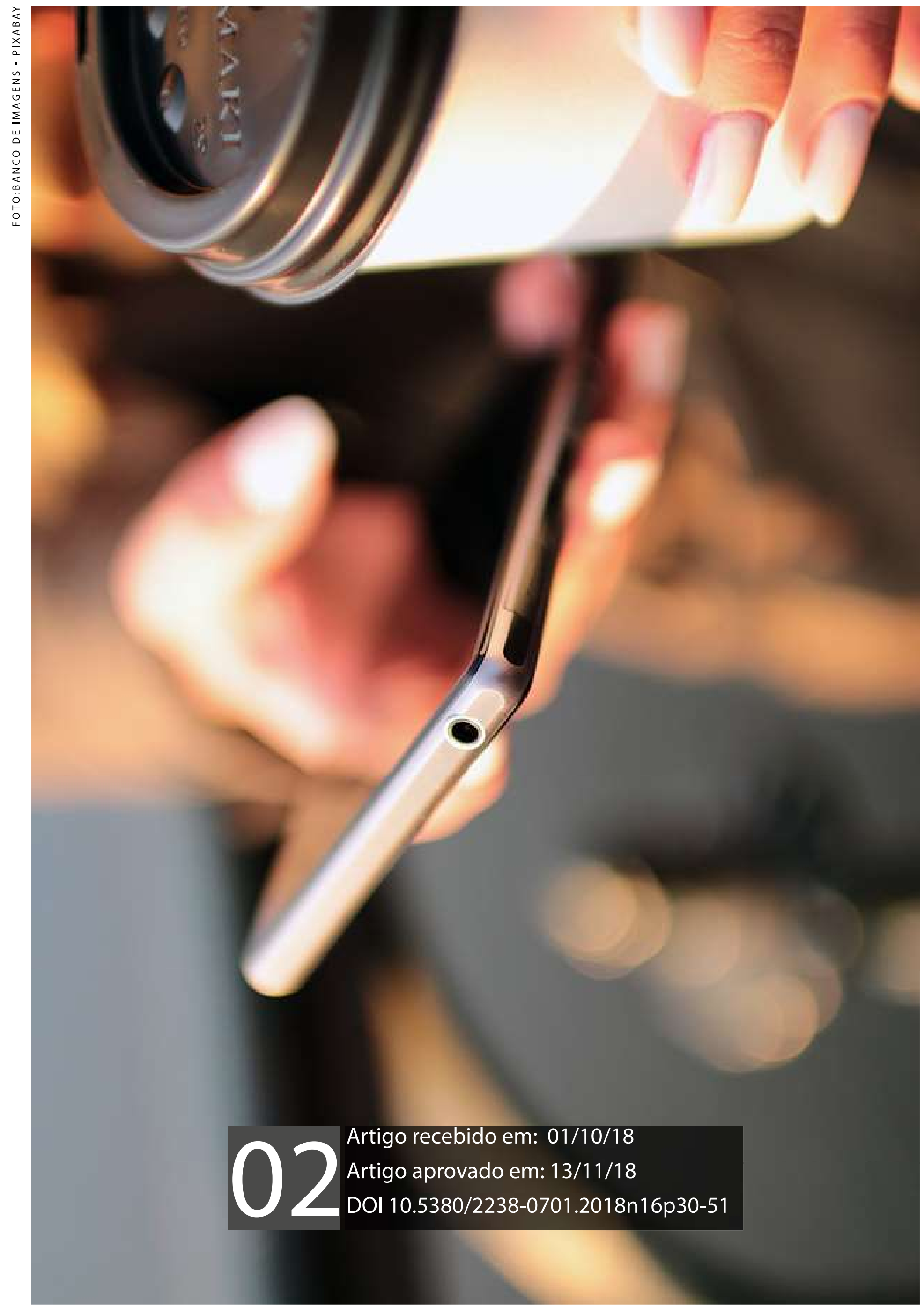


Dispositivo; Prefeitura de Curitiba; interação; redes sociais digitais; midiatização.

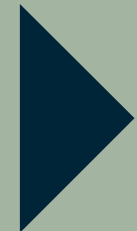




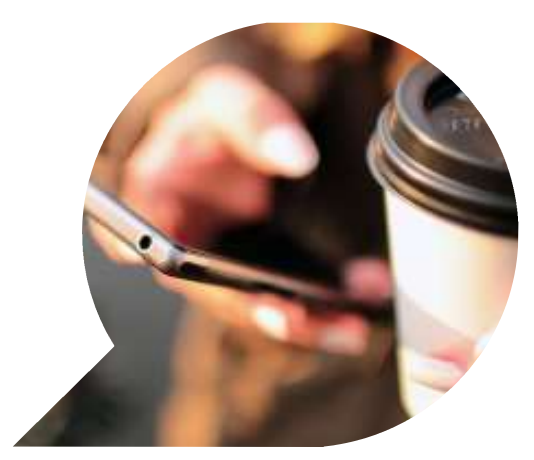

\section{Dispositivo Prefs: a configuração de um espaço interacional entre atores e instituição nas redes sociais digitais ${ }^{1}$}

\section{Prefs dispositive: the configuration of an interactive space between actors and institution in digital social networks}

Dispositivo Prefs: la configuración de un espacio interactivo entre actores e institución en las redes sociales digitales

\section{EDUARDO COVALESKY DIAS ${ }^{2}$}

Resumo: A aproximação conceitual com base na observação empírica das estratégias desenvolvidas pela Prefeitura de Curitiba nas redes sociais digitais entre 2013 e 2016 busca definir o "dispositivo Prefs" como um conjunto de operações comunicacionais empreendidas pela instituição e pelos atores em resposta aos objetivos estratégicos da instituição neste ambiente. Apresenta-se componentes e elementos, estratégias, movimentos e arranjos que colaboram para a montagem. Incidem, a partir daí, processos de regulação, disrupção e emergência de novas inteligibilidades. Por fim, considera que a perspectiva comunicacional do objeto é relevante para compreender relações de reconhecimento mútuo, indicadas pelas práticas interacionais entre atores e instituição. O trabalho é desenvolvido em pesquisa de doutorado em

1 Pesquisa financiada com bolsa Capes-PROEX.

2 Doutorando no Programa de Pós-Graduação em Ciências da Comunicação da Unisinos, E-mail: educovalesky@gmail.com 
andamento e visualiza os processos comunicacionais do objeto sob a ótica de uma sociedade em midiatização.

Palavras-chave: dispositivo; Prefeitura de Curitiba; interação; redes sociais digitais; midiatização.

Resumen: La aproximación conceptual basada en la observación empírica de estrategias desarrolladas por la Prefectura de Curitiba en las redes sociales digitales entre 2013 y 2016 busca definir el "dispositivo Prefs" como un conjunto de operaciones comunicacionales emprendidas por la institución y por los actores en respuesta a los objetivos estratégicos de la institución en este medio ambiente. Se presentan componentes y elementos, estrategias, movimientos y arreglos que colaboran para el montaje. Inciden, a partir de ahí, procesos de regulación, disrupción y emergencia de nuevas inteligibilidades. Por último, considera que la perspectiva comunicacional del objeto es relevante para comprender relaciones de reconocimiento mutuo, indicadas por las prácticas interactivas entre actores e institución. El trabajo se desarrolla en investigación de doctorado en curso y visualiza los procesos comunicacionales del objeto bajo la óptica de una sociedad en mediatización.

Palabras-clave: dispositivo, Prefectura de Curitiba, interacción, redes sociales digitales, mediatización.

Abstract: The conceptual approach based on the empirical observation of the strategies developed by City Hall of Curitiba in digital social networks between 2013 and 2016 aims to define the "Prefs dispositive" as a set of communication operations undertaken by the institution and the actors in response to the institution's strategic objectives in this environment. It presents components and elements, strategies, movements and arrangements that collaborate for the assembly. From this, there are processes of regulation, disruption and emergence of new intelligibilities. Finally, it considers that the communicational perspective of the object is relevant to understand relations of mutual recognition, indicated by the interactional practices between actors and institution. The work is developed in doctoral research in progress and visualizes the communicational processes of the object from the perspective of a society in mediatization.

Keywords: dispositive, City Hall of Curitiba, interaction, digital social networks, mediatization. 


\section{Introdução}

O trabalho a seguir integra pesquisa de doutorado em que se desenvolve uma análise mais ampla sobre o objeto em questão. A intenção do autor é expor algumas percepções preliminares que se encontram em processo e que estão no contexto de qualificação da pesquisa. Além disso, a pretensão é apresentar o funcionamento percebido do objeto a partir da noção de dispositivo interacional desenvolvida por Braga (2017) e que deriva de Foucault (1979).

Intitulo como dispositivo Prefs a soma entre o conjunto de operações empreendidas pela Prefeitura de Curitiba nas redes sociais digitais (majoritariamente Facebook, mas também Twitter, Instagram e Snapchat) e o conjunto de operações empreendidas pelos indivíduos em resposta aos objetivos estratégicos da instituição. A soma destas operações caracteriza um dispositivo interacional tentativo.

Considera-se que é possível observar os processos de formação de um dispositivo em diversas etapas: 1) a Prefeitura de Curitiba se posiciona no ambiente digital a partir de 2013 com o objetivo estratégico de fomentar a participação dos indivíduos na coleta de informações para a Lei Orçamentária Anual de 2013 (KLENK, 2017, p. 52); 2) as ações buscam responder urgências sobre como uma instituição burocrática estatal deve se adaptar a novos espaços de interação com os indivíduos - estrategicamente, observa-se tendências e posicionamentos de outros órgãos nas redes sociais digitais e arranja-se uma forma de atuação $(2017$, p. 52); 3) ativado por uma rede estabelecida entre vários elementos, o dispositivo Prefs começa a se consolidar a partir de um processo triádico: as ações regulatórias da instituição, as novas inteligibilidades ascendentes, co-produzidas pelos indivíduos, e as disrupções produzidas pelos indivíduos e agenciadas pelo próprio dispositivo.

Este dispositivo se estabelece e aqui é nomeado como Prefs por este ser o nome adotado no processo interacional tanto pelos indivíduos quanto pela Prefeitura para se referir a estes espaços, ou conjuntos de atuações da instituição nas redes sociais digitais. Esta estratégia de atendimento, interação e posicionamento começa a ser reproduzido por outras prefeituras brasileiras - de modos distintos, mas com alguns objetivos comunicacionais e políticos em comum.

Aos poucos, os discursos se consolidam, as experiências se multiplicam por meio de outras instituições, que interagem também entre elas como 
forma de reconhecimento e legitimação das estratégias comunicacionais; ao mesmo tempo, precisam lidar com as demandas, os contrapontos e as co-produções de sentido dos indivíduos na interação com estas instituições. $\mathrm{O}$ dispositivo Prefs, portanto, afirma-se como discurso referencial para o posicionamento institucional de prefeituras em redes sociais digitais - até que haja novas mudanças estratégicas, sejam de natureza regulatória, disruptiva ou de novas inteligibilidades.

A busca pela caracterização da dispositividade do objeto em questão é, também, um exercício particular de síntese. A proposta da atividade tem como objetivo descrever as etapas e os processos que consolidam ou encaminham as relações entre componentes e participantes em direção à formação de um dispositivo interacional. Mais do que uma descrição, este trabalho pretende produzir inferências sobre as dinâmicas produzidas no funcionamento interno e também com componentes externos.

O desafio da caracterização do dispositivo é compreendê-lo a despeito das definições institucionais e da percepção do "outro" sobre a consolidação de sistemas de funcionamento: é comum estarmos integrados, como partícipes do dispositivo, mesmo que racionalmente não estejamos cientes ou não nos reconheçamos como integrantes destes sistemas.

\section{Caracterizações do dispositivo}

Para caracterizarmos o dispositivo Prefs, é necessário descrever os componentes desta rede. A Prefeitura de Curitiba mantém uma série de meios de comunicação, utilizados com objetivos e estratégias específicos: site institucional (www.curitiba.pr.gov.br), Central 156, Colab.re, página no Facebook, perfil em Twitter, Instagram e Snapchat, além de jogos digitais como Clean City (coleta seletiva do lixo) e Alter (simulação de situações de inclusão de pessoas com deficiências). Mais recentemente, em contato com representantes da atual gestão, há a informação de que a Prefeitura mantém grupos ativos de contato com o cidadão também no WhatsApp.

Desde 2013, um conjunto de estratégias de comunicação começou a ser implementado com o objetivo de impulsionar a interação entre indivíduos. Até então, a Secretaria Municipal de Comunicação Social mantinha o site institucional e a Central 156 como principais espaços de oferta de serviços, respostas e interação entre os indivíduos e o Poder Executivo.

Conforme entrevistas, realizadas publicamente por pessoas que participaram da equipe de implantação das redes sociais da Prefeitura de Curi- 
tiba, em 2013 - Alvaro Borba e Marcos Giovanella -, a demanda surgiu após a eleição de Gustavo Fruet como prefeito em 2012. O objetivo era produzir uma estratégia que aproximasse a Prefeitura do cidadão curitibano (KLENK, 2017) com vistas à participação nas consultas públicas para a Lei de Diretrizes Orçamentárias e a Lei Orçamentária Anual de 2013.

A pesquisa realizada por Giovanella apontava diversas tendências em comunicação digital. No primeiro semestre de 2013, a equipe e a estrutura de trabalho foi montada, junto à Secretaria Municipal de Comunicação Social, e as ações via redes sociais começaram a acontecer no mês de junho.

A página entrou no ar às pressas, para que pudesse ser usada como ferramenta para as consultas públicas que na época colheram sugestões para a Lei Orçamentária Anual (LOA) e a Lei de Diretrizes Orçamentárias (LDO). Em 2013, as audiências foram transmitidas pela internet, em uma página dentro do site oficial do Município. $\mathrm{Na}$ época, o $\mathrm{Fa}$ cebook ainda não contava com recursos de transmissão ao vivo. Mas as redes sociais eram usadas para que a população interagisse com a Prefeitura durante as consultas públicas. (KLENK, 2017, p. 52)

A nova estratégia demandou, também, adaptações de uma instituição com processos já estabilizados - desde 1984, a Central 156 é o principal canal de atendimento da Prefeitura de Curitiba. O projeto original proposto em 2013 priorizava o atendimento ao cidadão por meio das redes sociais, com o objetivo de ampliar as ferramentas para além dos canais tradicionais. "A integração entre os sistemas e a implementação de um maior número de serviços online, no entanto, não se concretizou como esperado, principalmente por dificuldades operacionais e orçamentárias" (KLENK, 2017, p. 52-53).

Atualmente, não existem dispositivos legais que especifiquem, direta ou indiretamente, a utilização de espaços comunicacionais como as redes sociais digitais para a prestação de contas ou a participação dos indivíduos em questões de interesse público. No entanto, estas estratégias se colocam cada vez mais como necessárias para o provimento de informações públicas, de accountability, de participação, bem como são espaços estratégicos para o marketing político - sejam estes espaços utilizados para uma racionalidade instrumental ou comunicacional, nos termos de Jürgen Habermas, o uso em si é crescente tanto por parte dos órgãos públicos quanto por parte dos indivíduos na relação com estes. Ainda que seja facultativo o tipo de meio e o formato utilizado, as experiências são testadas tanto como 
parte dos deveres de transparência atribuídos aos órgãos públicos quanto como percurso natural de aproveitamento das tecnologias disponíveis para a divulgação dos atos públicos e políticos de gestão.

A Lei da Transparência (Lei $\mathrm{n}^{\circ} 12.527$ de 18/11/2011) define, no artigo 5, que "é dever do Estado garantir o direito de acesso à informação, que será franqueada, mediante procedimentos objetivos e ágeis, de forma transparente, clara e em linguagem de fácil compreensão" e, conforme o artigo 8 , "é dever dos órgãos e entidades públicas promover, independentemente de requerimentos, a divulgação em local de fácil acesso, no âmbito de suas competências, de informações de interesse coletivo ou geral por eles produzidas ou custodiadas".

Não há, portanto, nenhum dispositivo legal que obrigue órgãos públicos a utilizarem espaços digitais como forma de divulgação. Este conjunto de estratégias, quando levadas a cabo, ainda pertencem ao que costumamos chamar de "vontade política". A ideia de que as redes sociais digitais poderiam servir para um propósito ligado à administração pública, somada à demanda, ao plano de ações e ao provimento de recursos materiais para a efetivação da ação, atrelado à vontade política de execução, possibilitaram o avanço da estratégia. Em fluxo contrário, os indivíduos já presentes aos milhares nas redes sociais digitais mantinham demandas ao poder público em seus perfis pessoais, em conexão com círculos privados ou comunitários, distantes da percepção e do reconhecimento destas demandas por parte de integrantes dos órgãos competentes.

\section{Constituição do dispositivo Prefs: arranjo, desencadeamento e montagem}

A rede estabelecida entre estes componentes é o que chamamos de "dispositivo Prefs". Como afirmado anteriormente de forma breve, este nome surge no processo interacional entre indivíduos e Prefeitura - estrategicamente lapidado pela equipe de gestão a partir de práticas de marketing mas amplamente adotado pelo público em geral para se referir à Prefeitura de Curitiba nas redes sociais. A personificação e a antropomorfização de marcas é uma estratégia bastante utilizada e desenvolvida pela publicidade há décadas, teorizada a partir da década de 1990 por Aaker (1997) e Fournier (1998) que, ao agregar teorias e metodologias da Psicologia, argumentam que a personalização da marca se associa a questões de âmbito cognitivo e subjetivo do consumidor (CARRERA, 2016). Esta estratégia tornou-se 
prática recorrente no posicionamento de marcas, empresas e instituições não-humanas para se relacionar com os indivíduos aos quais são correlatos.

Os processos que interligam os componentes do dispositivo são dotados de dinâmicas que o tornam um objeto em constante transformação - é possível observar fluxos triádicos contínuos de tentativas de regulação, disrupção e produção de novas inteligibilidades nas relações que integram participantes internos e externos ao dispositivo Prefs. Todos estes fluxos, no entanto, fundam-se em sua gênese para "responder a uma urgência", como fala Michel Foucault, com a "predominância de um objetivo estratégico". É necessário abalizar os limites e as condições de gênese e montagem enquanto sujeito-pesquisador para que se perceba um equilíbrio entre estes processos, pois, da intenção à ação, um amplo espectro moral é possível de ser atribuído aos objetivos de montagem do dispositivo - otimistas ou pessimistas, positivos ou negativos.

O posicionamento adotado possui estratégias agregadas e compartilhadas entre vários campos: político, jurídico, mercadológico e midiático. Está sujeito, também, às sanções e às atribuições de legitimidade destes campos. Assim, observa-se que, politicamente, entre 2013 e 2016, há um intencional "descolamento" entre a imagem da instituição e a imagem do prefeito. A estratégia de personificação referida anteriormente trata de atribuir uma personalidade à instituição, dotada de sentimentos e racionalidades, desvinculada de Gustavo Fruet e sua gestão.

Evidentemente, ainda que a estratégia de comunicação visasse a um incremento na participação, a uma aproximação do cidadão com a prefeitura, havia um esforço institucional de produzir imagens positivas da Prefeitura e da cidade. Destaca-se este esforço como um ponto de tensão entre os parâmetros de uma comunicação pública ideal, fundamentada em preceitos deliberativos, e parâmetros pragmáticos encontrados na prática da experiência - um cálculo político, necessário para o equilíbrio entre as estratégias compartilhadas dos campos sociais que incidem sobre o dispositivo.

O dispositivo apresenta diferenças entre o objetivo desejado e o realizado e existem diversos fatores que contribuem constantemente para variar esta diferença - a tecnologia utilizada, os marcos legais, as reações externas, as reações internas, o contexto político, etc. São dinâmicas contínuas, que perpassam a existência do dispositivo enquanto há a possibilidade de regular o objetivo pretendido. A possibilidade de regulação do objetivo, no entanto, não determina que o dispositivo seja de natureza regulatória - pelo contrário, esta mesma substância pode ocupar espaços distintos na matriz 
triádica exposta anteriormente.

O dispositivo se constitui em função de um objetivo estratégico. No entanto, o duplo processo é o que garante a existência do dispositivo. Ora, o que garante tal existência se não houver continuidade neste duplo processo?

\section{Dinâmicas, contextos e processos: como opera a Prefs?}

A força triádica do dispositivo é observada na dinâmica que se pode observar no funcionamento e na ação que os participantes empreendem em torno dos objetivos estratégicos. Diversas miradas são possíveis de serem observadas, e cada ponto de vista permite visualizar dinâmicas que se relacionam a campos distintos e que, integrados, ajudam a fortalecer um processo estruturante.

Um destes pontos de vista está vinculado ao meio e à forma como o campo midiático incide sobre e lapida os objetivos estratégicos a partir de um agenciamento que não é do domínio regulatório da instituição Prefeitura de Curitiba. As estratégias levadas à prática estão vinculadas a capacidades tecnológicas.

Quando se especifica a página da Prefeitura de Curitiba no Facebook, observa-se que os conteúdos produzidos neste espaço da rede social digital estão sujeitos a lógicas da plataforma que agenciam as ações da instituição. Ainda que a Prefeitura, na gestão 2013-2016, afirme não ter utilizado anúncios pagos e ter trabalhado apenas com estatísticas orgânicas da plataforma, há a sujeição a lógicas algorítmicas produzidas pela própria plataforma e experimentadas, em um sucessivo movimento de tentativa e erro, com o objetivo de se perceber quais são as práticas que geram maior sucesso em relação ao objetivo proposto.

O alcance orgânico, por exemplo, é uma medida recorrente para metrificar o sucesso de ações de marketing, assim como o engajamento - que contabiliza curtidas e reações, comentários e compartilhamentos. O sucesso da Prefs como estratégia de comunicação e marketing gerou efeitos no comportamento adotado por outras prefeituras brasileiras para se posicionar nas redes sociais, como é o caso de grandes capitais, que dinamizaram o teor formal de seus conteúdos institucionais, mas também de cidades de menor porte, que observaram neste contexto uma oportunidade de se aproximar dos indivíduos.

O cálculo político é outro fator de avaliação do sucesso da experiência, que faz pesar efeitos positivos ou negativos e geram uma série de rearticu- 
lações. O dispositivo Prefs surgiu na gestão de Gustavo Fruet (2013-2016) e uma das principais características do posicionamento adotado era a desvinculação entre a imagem da instituição e do prefeito em exercício. Nas eleições de 2016, Fruet concorreu à reeleição e foi derrotado ainda no primeiro turno - Ney Leprevost e Rafael Greca concorreram no segundo turno. Greca, ainda em campanha e durante o período de transição após eleito, afirmava que a "Prefs" não iria continuar em sua gestão ${ }^{1}$. O que se viu, no entanto, foi a continuidade do processo, com arranjos distintos em função de novos preenchimentos estratégicos - houve uma diminuição do uso do humor no conteúdo e houve a tentativa de direcionar a distribuição do conteúdo para alcançar menos indivíduos de fora de Curitiba, conforme a atual coordenadora do departamento de redes sociais, Cristiana Alessi.

As plataformas utilizadas (Facebook, Instagram, Snapchat, Twitter) estão sujeitas a lógicas de mercado. Nada impede que todas elas deixem de ser utilizadas em um futuro breve. Enquanto isso não acontece de maneira definitiva, é necessário avaliar que mesmo espaços formais de comunicação institucional estão sujeitos às instabilidades de uma transição de gestão, por exemplo. A gestão de Greca no site institucional da Prefeitura de Curitiba criou filtros (figura 1) que demandam a definição de período de busca anterior a janeiro de 2017 para o acesso de notícias institucionais produzidas pela gestão anterior, o que não aconteceu nas redes sociais digitais - os motivos para isso podem ser muitos, mas a natureza regulatória da página institucional como canal de comunicação oficial da prefeitura permite um controle sobre estas ações, ao passo que não há um controle direto sobre as ferramentas das redes sociais. Isto não permite, por exemplo, automatizar a ocultação de conteúdos de gestões passadas sem que ocorram perdas para o atual modelo de gestão. Até aqui, bastante se falou sobre o processo descendente - da instituição para os indivíduos. No entanto, sem a intensa participação dos indivíduos no conteúdo produzido pela Prefeitura, o dispositivo jamais encontraria consolidações. Ao observar individualidades em interação com a Prefs, desde 2013 percebe-se que a instituição é acionada para a interação com pessoas de diversas localidades do país - muitas delas estão interessadas em se relacionar com o perfil em virtude da criatividade, do humor, dos memes e do compartilhamento de uma linguagem comum (figura 2), muitas outras demandam soluções para problemas da cidade, sejam de ordem

1 http://www.bandab.com.br/politica/greca-diz-que-capivara-vai-voltar-aos-parques-e-anuncia-fim-da-prefs-no-facebook/ 
administrativa, burocrática ou estrutural, bem como uma sorte de outras solicitações, reclamações ou elogios (figura 3).

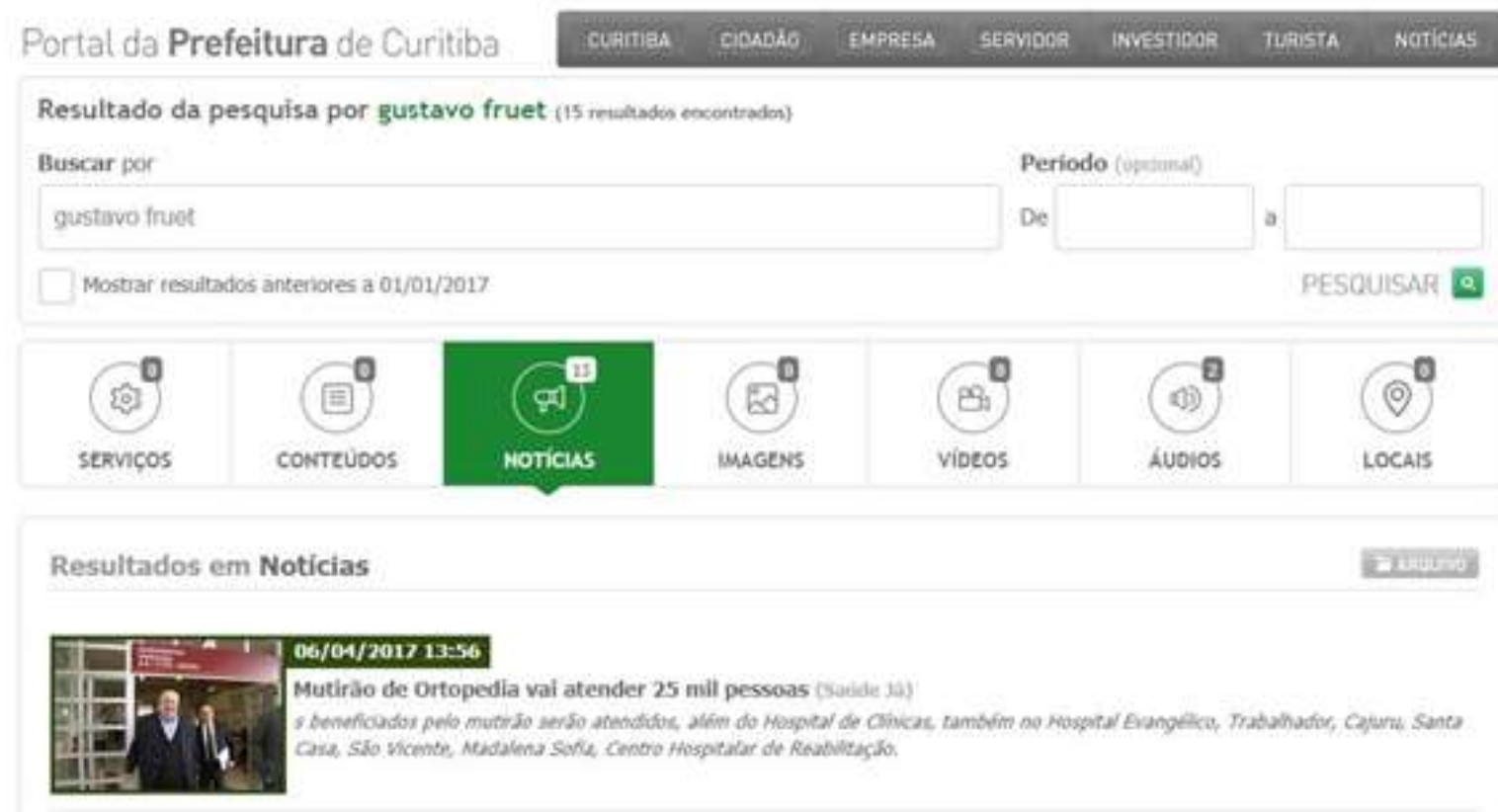

Figura 1: Resultados de busca na página da Prefeitura de Curitiba, com filtro para os resultados anteriores a janeiro de 2017 abaixo do campo de preenchimento "Buscar por". Fonte: Site oficial da Prefeitura de Curitiba

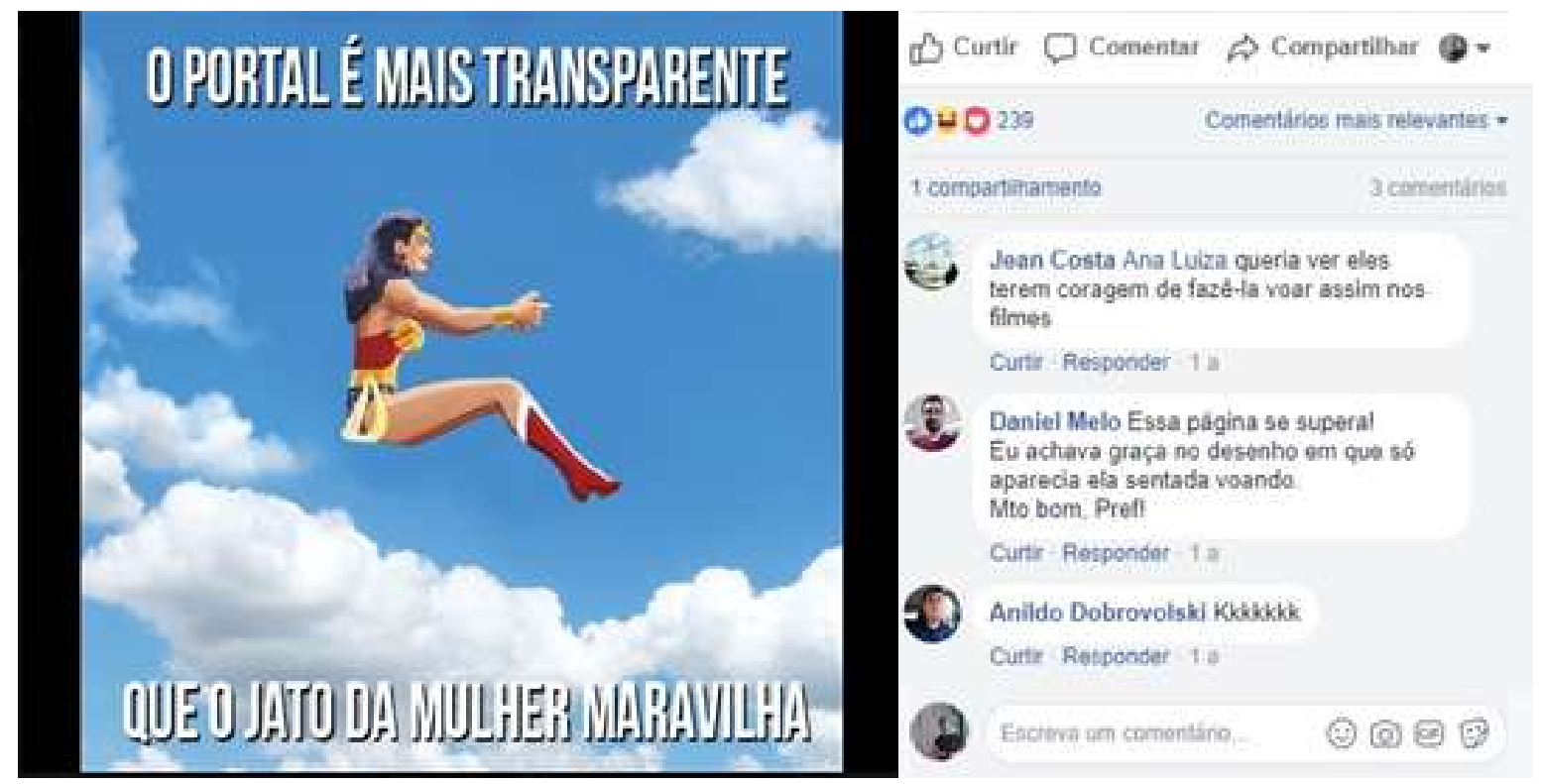

Figura 2: Publicação de dezembro de 2016 destaca a posição de Curitiba no Ranking Nacional da Transparência e utiliza referência à Mulher Maravilha. Interações, nos comentários, indicam interesse pelo desenho, não necessariamente pelo Portal da Transparência. Fonte: Página oficial da Prefeitura de Curitiba no Facebook. 


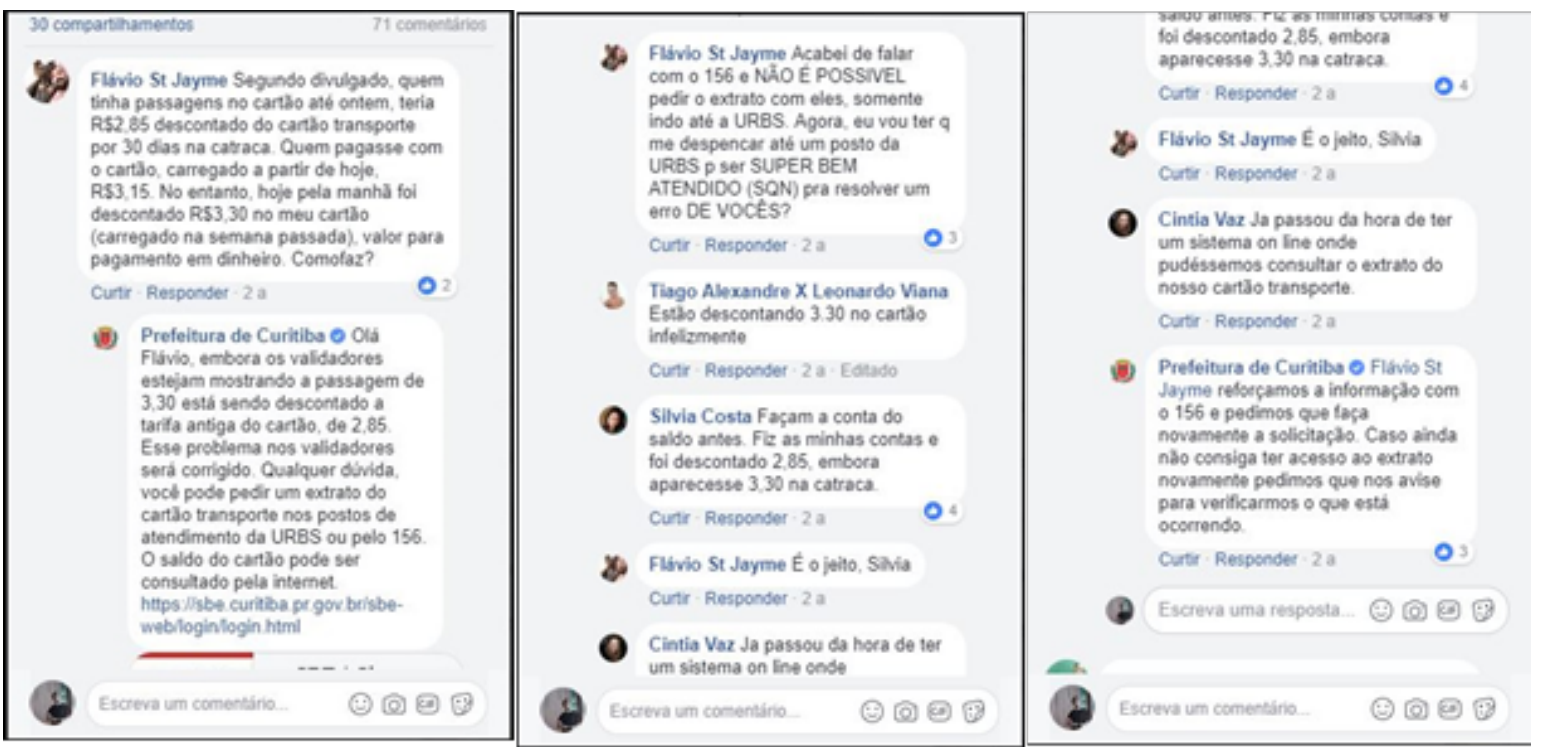

Figura 3: Indivíduo demanda informação e Prefeitura dialoga na tentativa de uma solução, enquanto outros participantes integram a conversa em publicação de janeiro de 2015. Fonte: Página oficial da Prefeitura de Curitiba no Facebook.

As interações entre indivíduos alcançaram certa popularidade nos frequentadores das redes sociais. $\mathrm{O}$ tráfego gerado na página reunia indivíduos muito além dos limites territoriais de Curitiba e Região Metropolitana, ou mesmo do Paraná, e confluía em interações, em uma mesma publicação, que demandavam respostas do Poder Executivo ao mesmo tempo em que se elogiava a Prefs, chamando-a de linda e recebendo como resposta um coração " $<3$ ".

No senso comum, sobretudo entre as pessoas que conhecem ou vivem em Curitiba, existem construções narrativas de que o clima da cidade, frequentemente frio e chuvoso, se reflete no humor e no comportamento dos curitibanos, tido como antipático. Este contraste de comportamento chamou atenção dos idealizadores e dos usuários e, inclusive, constituiu a ideia do posicionamento adotado pela Prefs nas redes sociais: o G1, em matéria ${ }^{2}$, destaca o argumento na voz do jornalista Álvaro Borba: "Falaram recentemente que o Twitter da prefeitura é o único que conversa com estranhos. A gente tem muito claro que esse não é um mito muito saudável para a identidade local, então a gente trabalha para desconstruir essa ideia de que Curitiba é antipática. Não, a gente fala com os outros, sim".

Neste movimento ascendente, a constante demanda do conjunto de indivíduos junto ao dispositivo Prefs, que, reitero, considera o conjunto de ações interacionais desenvolvidas por diversas plataformas de redes sociais

2 http://g1.globo.com/pr/parana/noticia/2013/11/prefeitura-brinca-com-capivaras-e-nome-de-curitiba-nas-redes-sociais.html 
digitais, colabora para a produção de tantas mais semioses quantas são as interações individuais com a instituição. Assim, disrupções acontecem e novas inteligibilidades surgem. Cito dois exemplos: um local, que se relaciona apenas a Curitiba; outro que surge em função do contexto local e se espalha como espaço de contraponto a outras prefeituras brasileiras.

A página "IPPUC, o Bárbaro", no Facebook, surge em setembro de 2014 como uma crítica às estratégias de planejamento urbano propostas pelo Instituto de Pesquisa e Planejamento Urbano de Curitiba (IPPUC), órgão vinculado à Prefeitura. As sátiras se relacionam a um bárbaro que tem a capacidade de cortar praças ao meio para um ônibus passar ou aplicar asfalto em áreas verdes.

Já o fenômeno "Prefrescura" ${ }^{3}$ surge também em 2014. A ideia da página era gerar um contraponto à personalidade da Prefeitura de Curitiba nas redes sociais digitais, dando espaço a problemas da cidade e questionando publicações da instituição. Assim como a experiência no dispositivo Prefs serviu como exemplo para formatar configurações de atendimento e posicionamento de diversas instituições públicas no país, sobretudo prefeituras, o fenômeno "Prefrescura" surgiu para denominar experiências empreendidas pelos próprios usuários em outras cidades (figura 4).

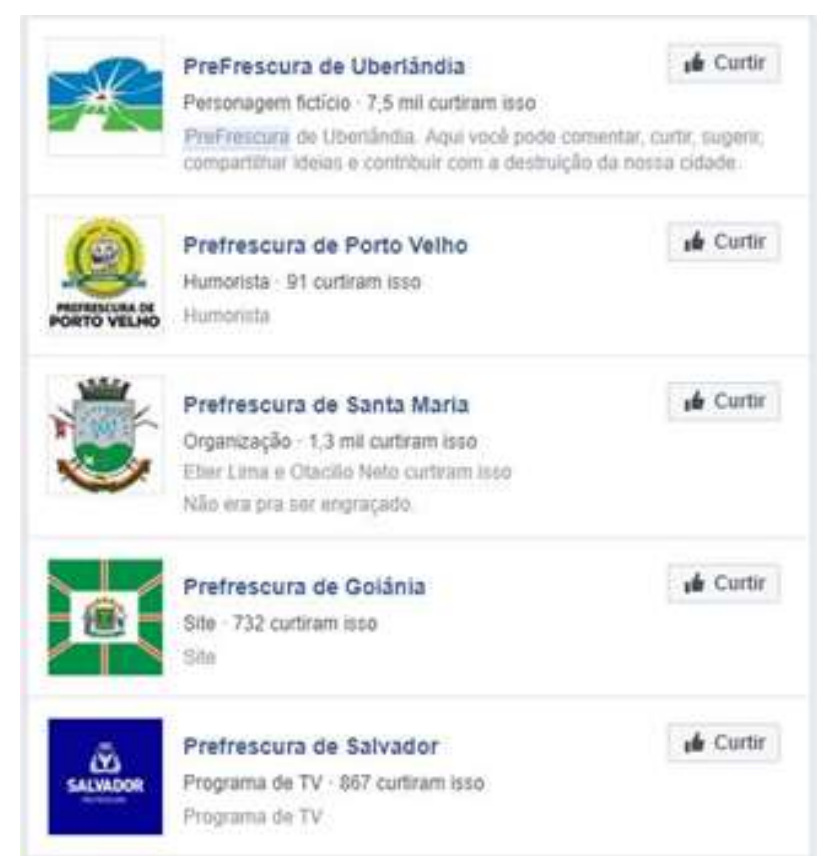

Figura 4: Resultados da busca por "prefrescura" no Facebook. A página "Prefrescura de Curitiba", a primeira a ser criada, está fora do ar. Fonte: Facebook.

3 https://geekpublicitario.com.br/4957/prefrescura-de-curitiba-os-perigos-de-uma-administracao-descolada-demais/ 
$\mathrm{O}$ arranjo se estabelece a partir de diversos pontos de vista e discursos. Um deles é bastante evidente: em campanha eleitoral, Rafael Greca afirmava que a Prefs acabaria em sua gestão; no entanto, até hoje a Prefeitura de Curitiba se autorrefere como Prefs nas redes sociais e, ainda que em menor frequência, mantém a utilização do humor em suas publicações. É necessário reconhecer que, desta forma, a gestão sucessora legitima a importância de dar continuidade ao posicionamento via redes sociais digitais.

Para o mercado de trabalho da comunicação, o dispositivo Prefs é um case de sucesso, que influencia a atuação de diversos outros órgãos públicos. No entanto, simplesmente estar nas plataformas e utilizá-las, ou possuir um departamento de redes sociais, ou utilizar uma linguagem informal, ou esforçar-se para responder às demandas, não são fatores suficientes para considerar que a Prefs determina qualquer tipo de comportamento. A Prefeitura de Curitiba não foi a primeira nem será a única instituição a adotar estas práticas, mas um conjunto de fatores colaborou para este sucesso, inclusive o fato de que nenhum órgão público brasileiro havia alcançado tamanha visibilidade em função de sua estratégia de comunicação via redes sociais e poucos órgãos estruturavam equipes de trabalho dedicadas a isto.

\section{Inferências sobre o circuito}

Klenk (2017) disserta sobre a oferta de conteúdo apresentada pela Prefeitura de Curitiba no Facebook. O trabalho realiza um levantamento sobre amostragem do conteúdo oferecido aos usuários durante os quatro anos de mandato do prefeito Gustavo Fruet - de março de 2013 a dezembro de 2016. Neste período, Klenk (2017) traça um panorama sobre as categorias temáticas oferecidas, as estratégias de comunicação recorrentes, a co-relação entre as temáticas e o engajamento observado. Além destes pontos, metodologicamente descritos, o trabalho aponta possíveis intencionalidades em nível de produção a partir de entrevistas realizadas de forma complementar à pesquisa.

Ao tecer considerações sobre a oferta de conteúdo, Klenk (2017) destaca a alta predominância de conteúdos classificados como Relacionamento (característica exclusiva de promover entretenimento e fortalecer o relacionamento com o público no Facebook). Para a autora, esta constatação pode ser explicada pela intenção manifesta pelos profissionais entrevistados, pelo objetivo de conquistar altas taxas de adesão e interação e oferecer "um cardápio de assuntos que coincidisse com o apetite dos usuários da rede" 
(KLENK, 2017, p. 85). A autora complementa que essa fórmula encontrou também, em alguns momentos, temas de interesse social "de algum modo mais pertinentes ao debate político e democrático" (2017, p. 85).

Porém, o que a página do Facebook da Prefeitura de Curitiba oferta aos atores é um dos componentes de um fenômeno comunicacional que complexifica a relação destes atores com a instituição política. Como objeto de pesquisa, apresentamos a concepção de do que se entende como "dispositivo Prefs". Antes, descrevemos algumas dimensões desta rede ampliada de comunicação para, após, explicitarmos algumas problematizações, dúvidas e limitações de pesquisa atreladas ao que se visualiza. O objetivo é que, ao fim deste processo, tenha-se mais claro o campo de observáveis em investigação.

Ainda que saibamos que um objeto empírico não é "uma coisa só", descrevê-lo é uma tarefa árdua porque exige o esforço de compreender o material em sua amplitude e abrangência sem recair em uma dispersão tamanha que o torne a referência do próprio funcionamento social a ponto de todos os fenômenos acontecerem ou se desenvolverem ao seu redor - um "empiricentrismo", com o perdão do neologismo. Soma-se a isso a necessidade de compreender que este objeto também não se caracteriza por um essencialismo que o perceba como "uma coisa em si".

Dito isso, compreendemos nosso objeto - recuperando uma metáfora de Pedro Gilberto Gomes - como uma árvore, que não pode ser explicada apenas pela soma de suas partes, mas pelos padrões de interconexões entre ela, o solo, o ar e a água. Foucault (1979, p. 364) colabora para este entendimento a partir do qual Braga (2017) desenvolve a ideia de dispositividade. Para eles, portanto, os componentes compreendem

um conjunto decididamente heterogêneo que engloba discursos, instituições, organizações arquitetônicas, decisões regulamentares, leis, medidas administrativas, enunciados científicos, proposições filosóficas, morais, filantrópicas. Em suma, o dito e o não dito são os elementos do dispositivo (FOUCAULT, 1979, p. 364).

Retomo aqui o problema de pesquisa norteador: de que maneiras determinadas práticas de democracia digital tentam resolver o problema comunicacional entre o cidadão e o campo político em uma ambiência social em midiatização? Realizamos, nessa perspectiva, o trabalho abdutivo, compreendido como articulações entre inferências indutivas e dedutivas preliminares (FERREIRA, 2017). 
O acompanhamento das dinâmicas de funcionamento das estratégias de comunicação da Prefeitura de Curitiba desde 2013 permitiu uma aproximação do pesquisador com os materiais empíricos como usuário, cidadão ou participante da interação, e a percepção de que se instalava uma forma de relacionamento relevante para a pesquisa nas ciências de comunicação.

Como informamos, desde 2013, um conjunto de ações de comunicação começou a ser implementado com o objetivo de impulsionar a interação entre atores e instituição. Até então, a Secretaria Municipal de Comunicação Social mantinha o site institucional e a Central 156 como principais espaços de oferta de serviços, respostas e interação entre os atores e o Poder Executivo.

Conforme entrevistas, realizadas publicamente por pessoas que participaram da equipe de implantação das redes sociais da Prefeitura de Curitiba, em 2013 - Álvaro Borba e Marcos Giovanella -, a demanda surgiu após a eleição de Gustavo Fruet como prefeito em 2012. O objetivo era produzir uma estratégia que aproximasse a Prefeitura do cidadão curitibano (KLENK, 2017) com vistas à participação nas consultas públicas para a Lei de Diretrizes Orçamentárias e a Lei Orçamentária Anual de 2013.

A partir daí, o órgão público desenvolveu e manteve uma série de meios de comunicação, utilizados com objetivos e estratégias específicos: sítio institucional (www.curitiba.pr.gov.br), Central 156, Colab.re, página no Facebook, perfil em Twitter, Instagram e Snapchat, além de jogos digitais como Clean City (coleta seletiva do lixo) e Alter (simulação de situações de acessibilidade para pessoas com deficiência). Mais recentemente, há também grupos ativos de contato via WhatsApp.

Ao observar as práticas comunicacionais, percebe-se uma interação intensa entre atores e de atores com a instituição - com ênfase para a página no Facebook. Duas inferências são produzidas a partir deste momento: 1) a linguagem informal, que rompe com uma tradição formal da comunicação de órgãos públicos, é o que chama atenção e dá visibilidade ao objeto; 2) a interação entre a instituição e os atores parece se consolidar no esforço de resposta da Prefeitura a várias demandas produzidas pelos usuários no meio.

Estas percepções se materializam em figuras ou metáforas, que buscam compreender algumas perspectivas do objeto empírico. Destaca-se algumas:

1. Arena discursiva: remete a um espaço em que os discursos estão em enfrentamento. É mais adequado pensar na figura sob uma 
perspectiva discursiva do que delimitá-la à normatividade da deliberação como avaliação de qualidade, o que a difere da ideia de "arena deliberativa" (BARROS, CARREIRO; 2016), sem descartar tais tensionamentos em sua dinâmica.

2. Resposta como catálise do circuito: a resposta dada publicamente pela Prefeitura às demandas de atores individuais catalisa o circuito de produção de sentidos e alimenta o potencial de participação individual. A satisfação do ator com a resposta ou a conversa entre outros atores não necessariamente garante a continuidade do circuito, pois, mesmo que insatisfatória, a resposta da instituição segue a produzir sentidos fora de seu controle regulatório.

3. Reconhecimento mútuo: ao ler a demanda do ator e prover uma resposta, percebe-se que há uma legitimação da Prefeitura ao ator, o que pode gerar o sentimento de reconhecimento (HONNETH, 2003; MENDONÇA, 2006; FERREIRA, 2017) ao participante da relação em função da resposta obtida. Da mesma forma, a ausência de resposta pode, também, gerar obstáculos na relação.

4. Estética "não-séria" da linguagem: utilizada como estratégia para a oferta de conteúdo da Prefeitura de Curitiba nas redes sociais, ela colabora para gerar visibilidade, tanto para atores que possuem envolvimento com a cidade quanto para os que não possuem relação. A estratégia perpassa transversalmente todo o processo de resposta e reconhecimento, incidindo sobre as interações entre ator e instituição, mas sem ser determinante para o funcionamento da relação (TRAESEL, 2016).

O exercício de produção de inferências é feito a partir da observação dos indícios que inicialmente configuram um fenômeno comunicacional a ser investigado. Os itens acima, bem como outros que venham a ser desenvolvidos, emergem da observação empírica e residem numa etapa de pesquisa que busca observar a experiência sem a aplicação de um arcabouço teórico que venha a distorcer a forma de ver o objeto. Braga (2017) ressalta a importância de explorarmos o que o senso comum pode contribuir para os objetos comunicacionais, bem como Ferreira (2016) indica a relevância de explorarmos as analogias, as metáforas, a criatividade e outros movimentos holísticos que possam colaborar para entender o que os objetos nos dizem antes de sua articulação teórica. 


\section{Caracterizações abrangentes e relações de força}

Para os indivíduos, o dispositivo Prefs pode representar muitas formas novas de relacionamento com a instituição responsável pelo Poder Executivo. Há o rompimento de uma barreira no atendimento que, antes, dificilmente se podia identificar. Há também a proximidade e a estratégia de personificação que aproxima e simplifica a forma com que uma instituição burocrática pode se relacionar com os indivíduos. Observa-se, acima de tudo, como ponto central para o desenvolvimento da tese de doutorado, uma relação entre indivíduo e instituição em que a estratégia de personificação contribui para o reconhecimento mútuo - o indivíduo é reconhecido pela instituição, que o reconhece como partícipe da relação, que por sua vez é reconhecida pelo indivíduo. Ao falar com uma instituição dotada de "sentimentos" (estrategicamente construídos), há a percepção de equidade na relação, dada a natureza antropomórfica da personalidade de marca construída para a Prefeitura.

Consolida-se, desta forma, um dispositivo interacional tentativo que habita um território de interseção entre diversos campos e possui um objeto comunicacional como referência central para seu funcionamento - o reconhecimento mútuo, que opera no plano da interação, no fluxo dialógico, e é atravessado por diversas semioses que participam deste fluxo concomitantemente. Esta dinâmica produz um desafio regulatório para a instituição e gera uma demanda crescente dos indivíduos, que podem ter suas demandas atendidas ou não. As respostas dadas pela instituição, satisfatórias ou não, retroalimentam o dispositivo com a oferta de novas produções de sentido aos indivíduos, o que instala um circuito de participação.

É neste sentido que o dispositivo Prefs emerge como um objeto comunicacional relevante para ser observado: que transformações este processo produz nas interações com instituições públicas? De que maneiras os indivíduos veem suas demandas contempladas por este dispositivo? Até que ponto a linguagem pode determinar o comportamento dos indivíduos ou delimitar a interação? Questões como essas podem ser produtivas para se pensar as formas com que relações até certo ponto institucionalizadas, formais e burocratizadas, como é a relação cidadão-prefeitura, podem ser transformadas por meio de estratégias de comunicação em que a semiose e a busca pelo reconhecimento das individualidades seja central para o desenvolvimento social e humano. 


\section{Referências bibliográficas}

BARROS, Samuel; CARREIRO, Rodrigo. O Facebook como plataforma para o comentário de notícias: uma análise da deliberatividade em cinco temas. In: MENDONÇA, R. F.; SAMPAIO, R. C.; BARROS, S. A. R. (orgs.). Deliberação on-line no Brasil: entre iniciativas de democracia digital e redes sociais de conversação. Salvador: EDUFBA, 2016.

BRAGA, José Luiz. Dispositivos interacionais. In: Matrizes Interacionais: a comunicação constrói a sociedade. Campina Grande. Eduepb, 2017.

BRAGA, José Luiz. O Senso Comum e a Comunicação. In: Capítulo de livro organizado pelo PPGCC-Faculdade Cásper Líbero. São Paulo. No prelo, 2017.

CARRERA, Fernanda. Identidade da marca e ambiente digital: Personificação, antropoformização e personalidade sob os desígnios da ciberpublicidade. Rizoma, Santa Cruz do Sul, v. 4, n. 2, p. 221, dezembro, 2016.

FERREIRA, Jairo. A construção de casos sobre a midiatização e a circulação como objetos de pesquisa: das lógicas às analogias para investigar a explosão das defasagens. Galáxia, n. 33, 2016.

FERREIRA, Jairo. As metamorfoses da circulação: fluxos às questões de reconhecimento. In: Paulo Cesar Castro (org.). A Circulação Discursiva: entre Produção e Reconhecimento. 1 ed. Maceió: EDUFAL, 2017, v. 1, p. 109-124.

FOUCAULT, Michel. Microfísica do poder. Rio de Janeiro: Editora Paz e Terra, 1979.

KLENK, Lenise A. Além das capivaras: análise da oferta de conteúdo na página a Prefeitura de Curitiba no Facebook. Trabalho de Dissertação. UFPR, 2017.

MENDONÇA, Ricardo F. Reconhecimento em debate: os modelos de Honneth e Fraser em sua relação com o legado habermasiano. Compolítica, 2006. 
TRAESEL, Francieli. O (não) sério e as organizações públicas: uma perspectiva pragmática do uso do humor na fanpage da Prefeitura Municipal de Curitiba. UFPR, 2016. 
AÇÃO MIDIÁTICA, n.16. Jul./Dez. 2018. Curitiba. PPGCOM-UFPR. ISSN 2238-0701

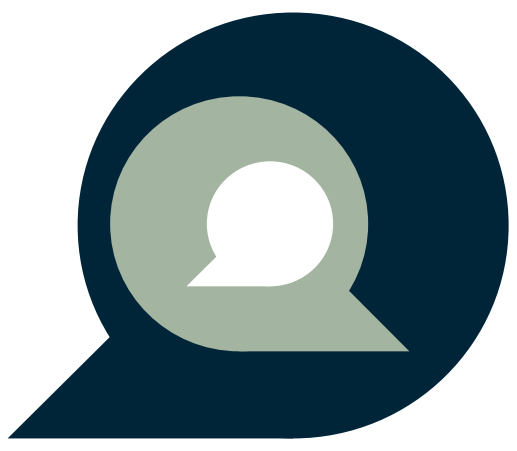

